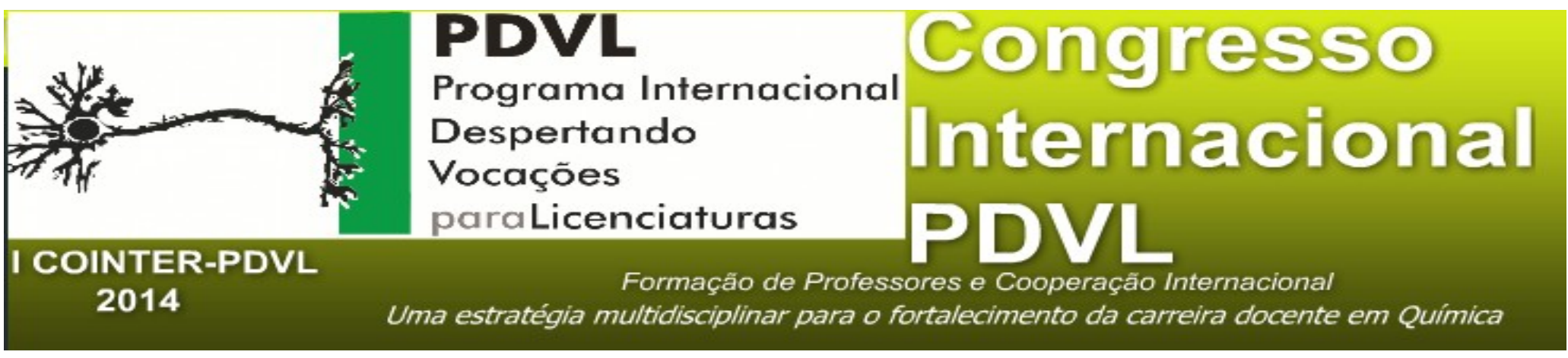

\title{
A COMPREENSÃO DOS CONCEITOS QUÍMICOS A PARTIR DA VISÃO DOS ALUNOS DO ENSINO MÉDIO
}

Apresentação: Pôster

Jaqueline Quintino da Silva'; Elié Paula Predi Dornelas de Souza²; Fabrício Lúcio Cansanção Lira; Johnnatan Duarte de Freitas ${ }^{4}$

\section{Introdução}

A Química é uma das disciplinas do ensino médio que os alunos mais relatam ter dificuldades. Os motivos são diversos, grande quantidade de conteúdos, fórmulas e cálculos complexos, tudo com muita teoria e pouca prática. Diante desse cenário, alunas Curso de Licenciatura do Instituto Federal de Alagoas, voluntárias do Programa Despertando Vocações para as Licenciaturas - PDVL, realizaram uma pesquisa com alunos do $1^{\circ}$ e $2^{\circ}$ anos do ensino médio da Escola Estadual Doutor José Maria Correia das Neves. Com a finalidade de investigar os principais fatores que afetam a compreensão em Química, a partir dos relatos desses estudantes. Tal pesquisa consiste num estudo de caso em que, a coleta de dados ocorreu a partir de questionários semiestruturados respondidos pelos participantes. Com essa proposta, foi possível compreender a

1Licenciatura em Química/Instituto Federal de Alagoas (IFAL) / Programa de Extensão Internacional Despertando Vocações para as Licenciaturas - PDVL /jaqueline.quintino6@gmail.com

2Licenciatura em Química/ Instituto Federal de Alagoas (IFAL) / Programa de Extensão Internacional Despertando Vocações para as Licenciaturas - PDVL / eliepaulap@gmail.com

3Professor de Química/Secretaria de Educação do Estado de Alagoas/ Programa de Extensão Internacional Despertando Vocações para as Licenciaturas - PDVL flclira@yahoo.com.br

4Doutor em Química / Instituto Federal de Alagoas (IFAL) / Programa de Extensão Internacional Despertando Vocações para as Licenciaturas - PDVL /johnnatan.duarte@ifal.edu.br 
visão dos discentes sobre a matéria em questão, bem como refletir sobre a prática docente do professor de Química.

\section{Fundamentação Teórica}

A Química pode ser definida como uma ciência que compreende a composição e as propriedades dos materiais que rodeiam nosso cotidiano, tanto no aspecto visível, quanto ao teórico e, também de modo representacional (LEAL, 2009, p. 13). Nessa perspectiva, essa ciência como disciplina, deve desenvolver nos alunos a compreensão dos fenômenos químicos presentes no dia a dia, bem como indivíduos críticos em relação aos avanços tecnológicos (PCNEM, 2000, p. 31).

O ensino de Química, como nas ciências em geral, demanda de práticas dinâmicas e articuladas à realidade dos estudantes no processo de ensino-aprendizagem dos conceitos. $\mathrm{O}$ tratamento metodológico dos assuntos deve sempre promover a contextualização e o cientificismo inerentes à ciência. Para isso, os professores devem ter conhecimento dos avanços científicos recentes e, a partir daí transmitir uma percepção dinâmica e não fechada da Ciência (CARVALHO; GIL-PÉREZ, 2011, p. 25). Assim, a aprendizagem é discutida a partir do tratamento metodológico feito pelo professor, em que o método de ensino-aprendizagem a ser escolhido, deve suscitar a atividade do estudante e não a passividade dele diante dos assuntos (BORGES, 2002, p. 294).

A concepção dos alunos diante das disciplinas que envolvem cálculos e teorias científicas complexas sempre é de dificuldade e impasse entre o teórico e o prático. Isso ocorre devido ao modo de ensino tradicional tão questionado, mas que continua a ser encontrado na escola. Mas, as pesquisas nessa área revelam novas ferramentas pedagógicas que facilitam a aprendizagem e, o rendimento dos alunos em sala. Nesse sentido a seleção planejada e cuidadosa dos assuntos, ligada à metodologia adequada, pode contribuir para mudanças significativas no o ensino de Química (KUWABARA, 2009, p. 153).

\section{Metodologia}

Para o desenvolvimento dessa proposta de cunho qualitativo, considera-se que este estudo de caso contempla a compreensão dos motivos que justificam a complexidade citada pelos alunos do ensino médio, quanto a Química. O estudo foi realizado numa escola pública da cidade de Maceió (AL),contando com a participação de 185 alunos distribuídos no $1^{\circ}$ e $2^{\circ}$ anos. O questionário 
semiestruturado foi a técnica utilizada para coletar os dados discutidos, com o principal objetivo de analisar as dificuldades apontadas pelos participantes em relação à compreensão da Química. Para isso, as etapas seguiram desde a percepção dos primeiros relatos ouvidos pelas voluntárias até a formulação e aplicação dos questionários. A efetivação desse momento será descrita a partir da leitura dos dados obtidos, com as respostas ao problema levantado.

\section{Resultados e discussões}

A representação e leitura dos dados obtidos se embasaram nas respostas dos questionários por parte dos alunos envolvidos, considerando os que reconhecem ter dificuldades e os principais fatores inerentes a essa situação. Numa perspectiva voltada a aprendizagem dos conceitos químicos, Leal (2009, p. 41) defende que "a produção discursiva em sala de aula, comandada pelo professor, deve buscar a permanente articulação dos diversos aspectos associados ao tema/conceito, garantindo assim uma significação rica e consistente dos assuntos tratados.”

Assim, no gráfico 1observam-se valores próximos entre os que declaram dificuldade e os que não a apresentam. Estes últimos que evidenciam a compreensão, somam $42 \%$ dos estudantes que dizem não ter dificuldade com a disciplina, isso pode significar que o tratamento metodológico dos conteúdos tem sido articulado de maneira interessante e interativa, inclusive com atividades experimentais e constante associação dos conceitos químicos ao cotidiano. Os 58\% que apresentam complicações na aprendizagem culpam principalmente os cálculos como difíceis e, com isso a Química também fica complicada. Isso implica num fator preocupante, pois o domínio da “linguagem Química” é de fundamental importância para se prosseguir nos estudos, e inclusive interpretar as transformações do meio que se está inserido (KUWABARA, 2009, p. 161).

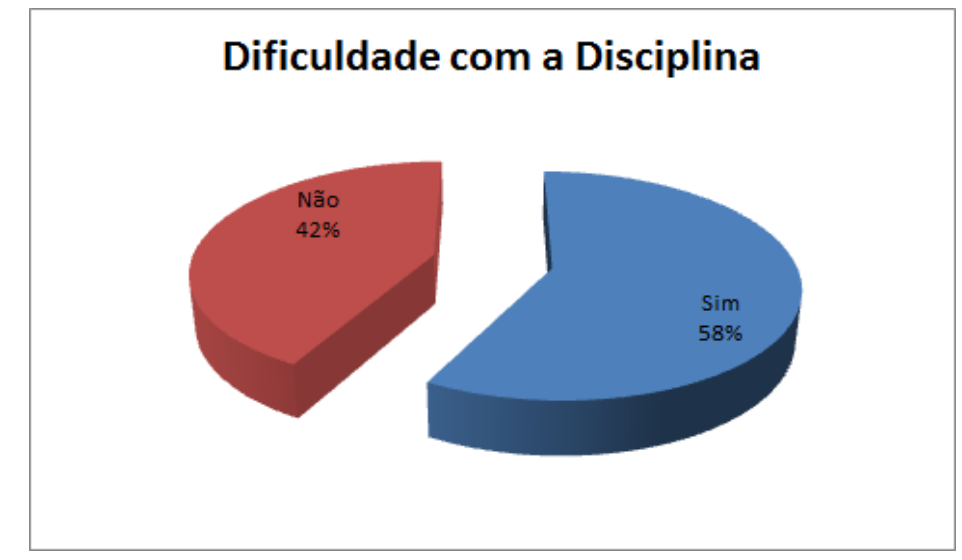


Gráfico 1. Compreensão da Química por parte dos alunos. Fonte: Própria.

Na exposição dos principais fatores que dificultam o entendimento da Química, o gráfico 2 revela a opinião dos alunos a cerca de tal discussão. Os cálculos são os causadores de 36\% das dificuldades encontradas. Isso é definido por Leal (2009, p. 40) como reflexo da “ênfase excessiva em fórmulas e equações, que beneficia a identificação dos estudos de Química com uma prática predominantemente memorística, relaciona a símbolos e palavras pobres de significação.” Dentre os que dizem entender a disciplina, 30\% afirmam que a explicação do professor é suficiente, no sentido de que os temas tratados são geralmente articulados de modo positivo. A complicação na hora de entender os conceitos afeta $21 \%$ dos estudantes, uma maneira de reverter esse quadro, seria familiarizar os alunos com os métodos científicos, facilitando o processo de aprendizagem da ciência (GIL-PÉREZ, 1994, p. 23).

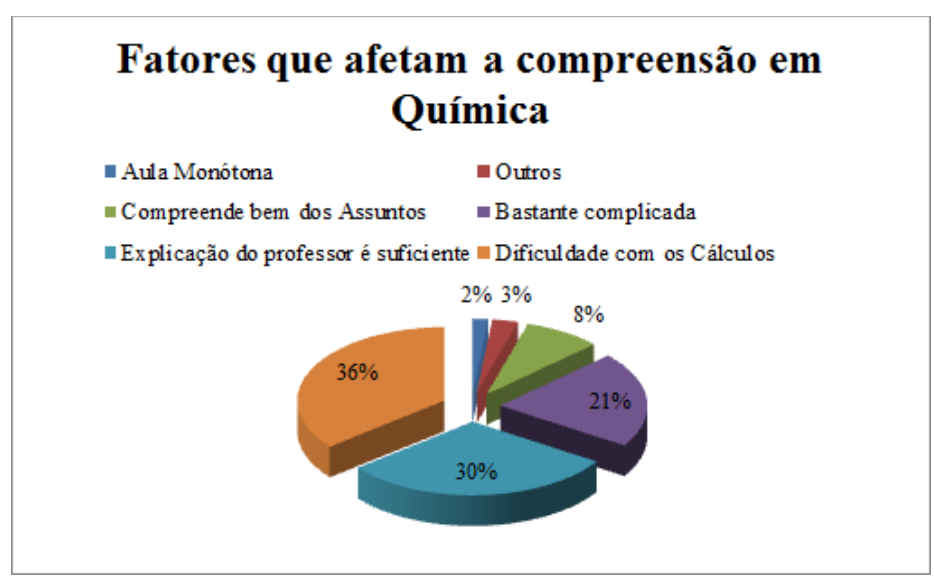

Gráfico 2. Elementos que definem a compreensão da Química. Fonte: Própria.

\section{Conclusão}

Os dados obtidos nos permitem compreender alguns dos principais elementos que permeiam tanto bloqueio ente os alunos e a Química. Assim, identificando esses motivos podemos questionar as metodologias mais utilizadas e, propor novas ferramentas que auxiliem na aprendizagem. A escola ainda tem a responsabilidade de formar indivíduos críticos e que conheçam a realidade ao seu redor, e o ensino de Química é fortemente encarregado de desenvolver habilidades que vão, desde o tratamento teórico até o manuseio de instrumentos na prática. Os conteúdos demandam a interpretação de fenômenos da natureza, não a formação de especialistas propriamente dita. Desse modo, essa pesquisa ressalta a importância de repensarmos a cerca da abordagem da disciplina em questão.

\section{Referências}


BORGES, A. T. Novos rumos para o laboratório escolar de ciências. Caderno Brasileiro de Ensino de Física, v. 19, n. 3, p.291-313, 2002.

BRASIL. MINISTÉRIO DA EDUCAÇÃO. SECRETARIA DE EDUCAÇÃO BÁSICA. Parâmetros nacionais curriculares nacionais. Ministério da Educação. Secretaria de Educação Média e Tecnológica: Brasília (DF), 2000. Parte 3.

CARVALHO, A. M. P.; GIL-PÉREZ, D. Formação de professores de ciências: tendências e inovações. 10. ed. v. 28. São Paulo: Cortez, 2011.

GIL-PÉREZ, D. Relaciones entre conocimiento escolar y conocimiento científico. In: PÉREZ, R. C.; DÍAZ, J. E. G. (coords.).Investigatión em La Escuela - El conocimiento escolar. Sevilla: Díada, 1994, p. 17-32.

KUWABARA, I. H. Química. In: KUENZER, A. Z. (Org.). Ensino médio: Construindo uma proposta para os que vivem do trabalho. 6. ed. São Paulo: Cortez, 2009, p. 152-161.

LEAL, M. C. Didática da Química - Fundamentos e práticas para o Ensino Médio. 1. ed. Belo Horizonte: Dimensão, 2009. 